\title{
Innovaciones introducidas en la legislación cooperativa de la República Oriental del Uruguay por la nueva Ley General de Cooperativas
}

\author{
Siegbert Rippe \\ Doctor en Derecho y Ciencias Sociales, Profesor Emérito \\ y Catedrático de Derecho Comercial \\ (Universidad de la República - Uruguay)
}

Recibido: $\quad 15.06 .09$

Aceptado: 6.07 .09

Sumario: I. Breve reseña de antecedentes normativos,- - II. Problemas jurídicos que presentaba la legislación cooperativa anterior,- - III. La nueva legislación cooperativa y las soluciones innovadoras que ella proporciona a los problemas planteados, - IV. A modo de conclusión.

Resumen: Se plantean los históricos problemas jurídicos de las cooperativas uruguayas y se exponen las principales soluciones incorporadas por la llamada «Ley General de Cooperativas», Ley N. ${ }^{\circ} 18.407$ de 24 de octubre de 2008, con acento en aquellas que tienden a resolver los referidos problemas y en las que suponen «novedades» en la materia cooperativa del país, entre las cuales se podrían señalar: la integración orgánica de la normativa cooperativa en un único texto legal; el reconocimiento legal de la definición, valores y principios cooperativos de acuerdo a la Declaración de Identidad Cooperativa (Manchester 1995); el objeto, alcance y límites del Acto Cooperativo, y la especialidad del Derecho Cooperativo; la admisión limitada de la transformación de las cooperativas, la especificidad, amplitud e intensidad normativa en materia de su gestión administrativa y económica asi como de integración de las cooperativas; la diferenciación funcional y administrativa entre promoción y control estatales; el tratamiento preferencial dado a las cooperativas de trabajo en los procesos concursales, etc.

Palabras clave: ley/es cooperativa/s, cooperativas, economía cooperativa, economía social.

Abstract: The historic legal problems of Uruguayan cooperatives and the main solutions that were incorporated in the "General Cooperative Law» (Law 18.407, October 24, 2008) are raised in this work. Here is also a special study of those articles that tend to solve problems and that ones that are «supposed» to be new in the cooperative area of Uruguay. Can be highlighted the articles referred to: organic integration of regulations in a unique legal text; legal recognition of definition, values and cooperatives principles according 
to the Cooperative Identity Declaration (Manchester 1995); object, reach and limits of the Cooperative Act, and the specialization in Cooperative Rigth; the limited admission of cooperative's transformation; specifications, ranges and norms intensity in their administration and economic formalities; functional and administrative differences between promotion and state control; the preference treatment that work cooperatives have in the bankarupcy process, etc.

Key words: cooperative/s laws (act/s), cooperative/s, cooperative economy, social economy. 


\section{Breve reseña de antecedentes normativos}

Es la ley 10.008 de 5 de abril de 1941 la que introduce formalmente a las cooperativas en la legislación nacional uruguaya, con la salvedad que dicha ley, derogada en 1984, sólo refería a la modalidad de Cooperativas Agrarias Limitadas y a las que consideraba un tipo de sociedad comercial.

Dicha ley marcó una tendencia, ya que posteriormente, y durante casi sesenta años, exactamente hasta el 24 de octubre de 2008, en que fue aprobada la Ley General de Cooperativas, la temática normativa del cooperativismo y de las entidades cooperativas fue abordada a través de leyes y reglamentos acotados, aislados, asistemáticos, que regulaban modalidades cooperativas específicas en función de su objeto social o actividad económica, con algún matiz en algunas modalidades cooperativas, que admitían variantes de formas o submodalidades, generalmente derivadas de modos diferentes de realización de dichas actividades económicas.

Es así que el panorama de la normativa nacional que regulaba en lo fundamental el fenómeno cooperativo entre 1941 y 2008 se componía básicamente de normas legales y reglamentarias específicas relativas a cooperativas: de producción, de consumo, de vivienda, de ahorro y crédito, agroindustriales, agrarias y sociales, sin perjuicio de otras puntuales, bien referidas a ciertas actividades que en el marco de normas determinadas podían también ser realizadas bajo ciertas condiciones por cooperativas (asistencia médica, seguros, garantía recíproca), bien relacionadas con las cooperativas en general (proceso constitutivo y personería jurídica, aplicación subsidiaria de la ley de sociedades comerciales, control estatal).

\section{Problemas jurídicos que presentaba la legislación cooperativa anterior}

Problema 1. Tratamientos legislativos y reglamentarios múltiples y heterogéneos, en perjuicio de la unidad conceptual y formal del fenómeno cooperativo.

La legislación era desconexa, insuficiente, con vacíos e incoherencias. La falta de una ley general de cooperativas y la existencia de leyes especiales por objeto o actividad determinaban dificultades en la concepción y el tratamiento unitario del fenómeno cooperativo que es en esencia único y común; incluyendo inconsistencias y contradicciones en la definición y regulación legal de aspectos generales de la organización 
y funcionamiento cooperativos y limitaciones en la posibilidad de constituir cooperativas para realizar actividades distintas a las previstas en la legislación entonces vigente, considerando la especificidad y taxatividad objetivas de cada una de las modalidades reconocidas por el sistema jurídico-cooperativo nacional entonces existente.

Problema 2. La confusa, incongruente y equívoca calificación jurídica de las cooperativas, en perjuicio de la propia identidad y especificidad de las cooperativas.

El punto tenía relación con la entonces discutida y discutible naturaleza jurídica de las cooperativas, ésto es, si eran asociaciones o sociedades, si eran entidades civiles o comerciales, o si, en definitiva, eran nuevas modalidades de agrupación de personas y recursos paralelas a aquellas.

El tratamiento legal de las cooperativas en la pasada legislación no fue uniforme, por el contrario, se hacía referencia en algunos casos a sociedades comerciales o ello resultaba implícito por su forma o por su actividad, en otros, de sociedades cooperativas, ni civiles ni comerciales, y en otros, simplemente, de cooperativas. Por lo tanto, existía heterogeneidad legislativa para un fenómeno jurídico único, que se traducía adicionalmente en la aplicación subsidiaria de regímenes diferentes que conspiraban contra la unicidad del sistema cooperativo, sin perjuicio, además, de la manifiesta incompatibilidad de la declaración legal, expresa o implícita, de mercantilidad para algunas modalidades cooperativas, inconsistente asimismo con características que la propia legislación cooperativa les reconocía, propias del fenómeno cooperativo y contradictorias con la propia concepción jurídico-positiva de las sociedades comerciales.

Existieron, sin embargo, otros tipos de normas legales que se constituyeron en avances respecto de la no comercialidad de las cooperativas: la primera, la relativa a las cooperativas de vivienda, (ley 13.728, de 1968) que no habilitaba ninguna interpretación o extensión analógica de carácter comercial a las mismas; la segunda, la incorporación del acto cooperativo para calificar las relaciones entre las cooperativas y sus asociados y entre las cooperativas entre sí, descartándose expresamente la condición de acto de comercio de esas relaciones o negocios, concepto que únicamente fue recogido en la legislación anterior en el decreto-ley 15.645 sobre cooperativas agrarias, de 1984; y la tercera, la circunstancia de que la ley de sociedades comerciales (ley 16.060, de 1989), si bien permitió la aplicación subsidiaria de la misma a las cooperativas, por un lado, no las incluyó entre los tipos societarios-mercantiles específicamente regulados por aquella, por otro lado, 
declaró expresamente que las cooperativas se seguirían rigiendo por sus leyes especiales y, por último, sólo admitió la referida extensión en lo no previsto por aquellas leyes cooperativas y solo en cuanto fuera compatible (ley citada, art. 515).

Problema 3. Intensos y complejos sistemas y estructuras de contralor estatal, en perjuicio de la libre formación y desarrollo de las cooperativas

Hasta 1990, el Poder Ejecutivo aprobaba los estatutos de las cooperativas, les otorgaba la autorización para funcionar y la personalidad jurídica, las controlaba, les podía retirar dicha autorización y promover incluso su disolución y liquidación, atribuciones estatales que no estaban conferidas de la misma manera tratándose de otros tipos societarios, salvo excepciones a veces vinculadas con la particularidad de sus actividades más que con la propia forma social adoptada.

Ese excesivo, atomizado y discordinado sistema de contralor estatal determinaba por su parte una actitud más cuasi paternalista del Estado hacia las cooperativas, incompatible con la naturaleza de las mismas, atentatorio, además, contra su crecimiento autónomo, independiente y responsable.

En materia de obtención de la personalidad jurídica, esto se mantuvo hasta la aprobación de la ley 16.156, de 1990, que facilitó su constitución y obtención de personería jurídica, a la vez que la ley 16.736, de 1995, centralizó y aligeró su control, en algunos casos, de manera absoluta o discriminatoria, sin perjuicio de soluciones específicas para ciertas modalidades cooperativas.

Problema 4. La deficiente regulación legal de la gestión cooperativa

Existía una limitada e insuficiente normatividad de la gestión social, en perjuicio de la organización, desarrollo y consolidación de la empresa cooperativa.

Si la cooperativa debía ser capaz de integrar los principios cooperativos con el esquema empresarial propio de las actuales unidades económicas, tal conciliación conceptual no se lograba generalmente, disociación a la que habían contribuido las propias deficiencias de la legislación correspondiente, que había privilegiado el respeto a los principios cooperativos en desmedro de una apropiada regulación de la gestión y administración societaria y empresarial de las entidades cooperativas, atento a que las disposiciones legales y reglamentarias en la materia eran escasas en general, y concedían una amplia y tal vez excesiva libertad a los estatutos sociales. 
Problema 5. La ausencia de un apropiado régimen jurídico de los aspectos económico-financieros de las cooperativas, en perjuicio de su desarrollo y consolidación

La cuestión económico-financiera era uno de los mayores y más extendidos problemas de las cooperativas, tradicionalmente atribuidos a la escasez de gerentes y personal preparado, a la débil estructura interna, a la insuficiente capitalización y a la inflación.

La legislación cooperativa no fijaba en general mínimos de capital social, tampoco, en consecuencia, de suscripción e integración: no se motivaba la aportación de capital de los asociados a la cooperativa, más allá de los mínimos estatutarios, ni otras modalidades de aportación; el único fondo obligatorio era, en general, el de Reserva Legal, y relativamente bajos los porcentajes de asignación de excedentes sociales para su integración.

La ausencia de un marco jurídico-económico y financiero idóneo, no permitía, no apoyaba, no estimulaba, la necesaria capitalización de las cooperativas, comprometiendo la realización del objeto social en cuanto actividad indispensable para alcanzar los fines de servicio de las mismas.

Problema 6. Insuficiente tratamiento de la integración cooperativa, en perjuicio de su misma subsistencia y de la unidad y coordinación del sistema cooperativo

El marco normativo anterior carecía de una disciplina integral. Algunas modalidades tenían disposiciones específicas, pero la integración era, y es, un fenómeno global que requiere un tratamiento único, y en la medida que ello no existía, esas carencias de nuestra legislación repercutían en la efectividad y eficiencia del fenómeno mismo. En definitiva, pocas normas legales sobre la materia, tratamiento limitado e irregular, escaso interés legislativo por impulsar la integración cooperativa.

Problema 7. El insuficiente y heterogéneo sistema legal do apoyo al desarrollo de las cooperativas, que se traducía en restricciones en el fenómeno cooperativo, en perjuicio de la estabilidad y desarrollo del cooperativismo

El apoyo estatal al cooperativismo era, y es, en definitiva, una decisión política El poder político puede fomentarlo, desestimularlo o, simplemente, abstenerse o ignorarlo.

La legislación cooperativa mostraba, en general, tanto una actitud positiva del Estado hacia el fenómeno cooperativo, como una coincidencia en los medios de apoyo utilizados para favorecer el desarrollo de las cooperativas nacionales, particularmente basados en exenciones 
tributarias, de diverso grado de intensidad, según modalidades sociales.

Por otro lado. Algunas modalidades cooperativas que tenían en común la satisfacción de necesidades básicas de los asociados - cooperativas de consumo, de vivienda y de ahorro y crédito- tenían la facultad legal de ordenar retenciones de ingresos de aquellos para cubrir las obligaciones contraídas por los mismos con las entidades correspondientes; pero era una medida que atendía a prevenir su descapitalización, más que a fomentar su desarrollo, y no implicaba obligaciones directas por parte del Estado.

Otras modalidades — caso de las agroindustriales y agrarias - podían obtener créditos o préstamos preferenciales o facilidades para exportación directa de sus productos; pero no se reglamentaba el otorgamiento de dichos beneficios, por lo que su cumplimiento y condiciones de operatividad dependían exclusivamente de las políticas y decisiones de los prestadores de esos servicios financieros.

La promoción, difusión y educación cooperativas por parte del Estado - previstas en la legislación anterior para las cooperativas de vivienda y agrarias, parcialmente para las agroindustriales- eran enunciaciones de meros propósitos en cuanto tampoco el Estado las asumía como acciones obligatorias y su efectiva realización también dependía de las resoluciones que adoptaran las entidades públicas competentes para esos efectos.

La organización del Estado para el fomento cooperativo era, por su parte, parcial y limitada, y estaba dividida.

En 1991, el decreto 128/991 creó, en la órbita de la Oficina de Planeamiento y Presupuesto de la Presidencia de la República, la Comisión Honoraria del Cooperativismo, institucionalizando de esa forma un esfuerzo de relacionar al gobierno nacional (representado por tres miembros designados por el Poder Ejecutivo) y al movimiento cooperativo a través de la Confederación Uruguaya de Entidades Cooperativas (CUDECOOP, representada por dos miembros en la referida Comisión), con cometidos de asesoramiento al Poder Ejecutivo y de promoción del sector.

En resumen, lo importante para cambiar la realidad antes descripta era lograr la unidad y coherencia de las políticas estatales, la jerarquización de las actividades de fomento y la coordinación en las decisiones y acciones, para la efectiva promoción y desarrollo del cooperativismo nacional, y los reiterados esfuerzos por impulsar una normativa coherente y apta a esos fines, ya desde 1973, recién culminaron en el año 2008 con la aprobación de la Ley General de Cooperativas. 


\section{La nueva legislación cooperativa y las soluciones innovadoras que ella proporciona a los problemas planteados}

La Ley 18.407, de 24 de octubre de 2008, Ilamada Ley General de Cooperativas, tiene como fuentes legislativas fundamentales, en primer lugar, la llamada "Ley Marco para las Cooperativas de América Latina» de la Alianza Cooperativa Internacional $(\mathrm{ACl})$, la normativa cooperativa uruguaya, cuya parcial reseña realizamos anteriormente en cuanto a normas legales y reglamentarias, a las que se agregan las estatutarias, así como disposiciones extraídas del derecho español, cuya primera ley general de cooperativas data de 1996, luego reformulada en 1987 y 1989, de la ley que regula las cooperativas en la República Argentina desde el año 1973, y también del derecho positivo en la materia de otros países sudamericanos, tales como Brasil, Paraguay y Chile, que cuentan con leyes generales en la materia desde 1991, 1994 y 2002, respectivamente, más las enseñanzas y experiencias del propio que hacer cooperativo.

a) Solución al problema 1: "Tratamientos legislativos y reglamentarios múltiples y heterogéneos, en perjuicio de la unidad conceptual y formal del fenómeno cooperativo»

El texto legal que regula ahora las cooperativas y reconoce al sector cooperativo como tal (art. $1 .^{\circ}$ de la ley) se compone de 224 artículos y está estructurado en cuatro Títulos: el primero, contiene Disposiciones Generales comunes a todas las cooperativas, el Título II, se refiere a las Cooperativas en Particular, el Título III estatuye lo referente, por una parte, a la promoción de las cooperativas y, por otra parte, lo relativo al control estatal de las mismas, y el último título reúne Disposiciones Especiales y Transitorias que incluyen diversas disposiciones habituales en una ley de estas características, generales y necesarias, tales como lo relativo al Registro Nacional de Cooperativas, control de asambleas, retenciones, régimen tributario, etc.

La Ley General de Cooperativas constituye un instrumento jurídico adecuado para solucionar el primer problema planteado por la legislación anterior, es decir, la anarquía de la legislación cooperativa nacional, a través de una ley general que reconoce la unidad sustantiva de las cooperativas en cuanto formas jurídicas regidas por iguales principios y similares reglas de organización y funcionamiento y que acepta a su vez las diversidades motivadas por las particularidades de los respectivos objetos sociales o las aconsejadas por la propia experiencia y realidad del cooperativismo nacional.

La ley que nos ocupa resulta pues, amplia y extensa, características de las que participa especialmente el Título I «Disposiciones Generales», 
acorde a la necesidad de comprender en ella las mayores posibilidades de tratamiento homogéneo de las cooperativas en su conjunto, y extender la regulación legal a la mayor cantidad de aspectos posibles de las mismas: extensión y amplitud que resulta pertinente atento a las anteriores experiencias legislativas que ya observamos como dispersas, inconexas e incompletas y en definitiva, limitantes del desarrollo cooperativo.

El Título II de la ley, como ya lo anticipamos, trata "De las Cooperativas en Particular», y siendo la parte general suficientemente amplia y flexible, deriva a la parte especial sólo aquellas disposiciones que son particulares a la naturaleza propia de las actividades específicas y que se reflejan en reglas concretas de operación derivadas de las mismas.

Es de destacar que si bien la ley establece una clasificación de cooperativas por objeto o actividad social, no descartó la posibilidad de nuevas, posibles actividades, y estableció expresamente que la clasificación contenida en la ley no obsta a la constitución de otras cooperativas, con tal que quede determinada la actividad y los derechos y obligaciones de los socios, en cuyo caso se aplicará la normativa prevista para la clase de cooperativas con las que aquéllas guarden mayor analogía.

El artículo 3. ${ }^{\circ}$ define el régimen y derecho aplicable a las cooperativas, es decir, en especial, las disposiciones de la ley y en general, el derecho cooperativo, declarando asimismo la supletoriedad de la ley de sociedades comerciales en lo no previsto y en cuanto sea compatible. Una solución de aplicación que repite la que ya estaba dispuesta en el art. 515 de la ley 16.060, ley de sociedades comerciales, artículo que la ley general deroga expresamente pero que reproduce a la letra en el art. $3^{\circ}$, citado, de que la nueva ley cooperativa, seguramente en la certeza del legislador de la que ley societaria, por su misma extensión (más de 500 artículos), nivel de elaboración y detalle, precisión de institutos societarios múltiples, antigüedad y experiencia de interpretación y aplicación doctrinaria, judicial administrativa y su periódica actualización legislativa (desde 1989), no dejaba de ser un referente obligado e insustituible para interpretar y aplicar la ley general, en lo que fuera pertinente y compatible.

Establece asimismo la definición de derecho cooperativo, como el «conjunto de normas especiales, jurisprudencia, doctrina y prácticas basadas en los principios que determinan y regulan la actuación de las organizaciones cooperativas y los sujetos que en ellas participan».

Dado lo expuesto, concluimos que en lo atinente al problema de dispersión e incoherencia que planteaba la anterior legislación, la llamada Ley General de Cooperativas responde exitosamente a la necesidad de unificar el Derecho Cooperativo en un único texto legal y resulta un instrumento esencial para permitir su desenvolvimiento autárquico en el espacio 
jurídico asociativo-nacional, sin perjuicio de que la raigambre del Derecho Societario obligue, en algún o más de un caso, a recurrir, subsidiariamente, a las disposiciones de la ley 16.060, de Sociedades Comerciales.

b) Soluciones al Problema 2: «La confusa, incongruente y equívoca calificación jurídica de las cooperativas, en perjuicio de la propia identidad y especificidad de las cooperativas».

La Ley General de Cooperativas ha proporcionado una solución acorde a la doctrina más recibida del Derecho Cooperativo al segundo problema planteado, esto es, a las calificaciones jurídicas erróneas y confusas de las cooperativas, en perjuicio de la propia identidad y especificidad de dichas entidades.

En efecto, el eje de la nueva ley se centra en el reconocimiento de que las cooperativas son entidades jurídicas con características propias y distintas a las de las sociedades civiles y comerciales, y que se rigen, por ende, por un derecho especial, el derecho cooperativo.

Ya mencionamos que en su artículo $1 .^{\circ}$ la Ley General de Cooperativas, (en adelante «la ley general») establece su objetivo y reconoce no sólo a dichas entidades para las que formula una regulación especial, sino también la existencia de un "sector cooperativo» y al armonizarlo con el artículo $2 .^{\circ}$, que en forma programática pero sin duda relevante, declara a las cooperativas de interés general e instrumentos eficaces para contribuir al desarrollo económico y social, al fortalecimiento de la democracia y a una más justa distribución de la riqueza, está reconociendo que dicho sector opera con características singulares e intransferibles en el quehacer económico nacional, acorde a las disposiciones de un derecho específico, el Derecho Cooperativo.

El artículo $4 .^{\circ}$ de la ley establece el concepto de cooperativas, definiéndolas como... "asociaciones autónomas de personas que se unen voluntariamente sobre la base del esfuerzo propio y la ayuda mutua», para satisfacer sus necesidades económicas, sociales y culturales comunes, por medio de una empresa de propiedad conjunta y democráticamente gestionada», definición acorde, sustancialmente, con la aprobada por la $\mathrm{ACl}$ en el Congreso de Manchester de 1995 a la que agrega dos elementos operativos: "sobre la base del esfuerzo propio y la ayuda mutua, y admite que las entidades por ella reguladas puedan revestir la forma de cooperativas de primer, segundo y ulteriores grados, de acuerdo con las especificidades que la misma prevé.

Como un elemento más de singularidad, el artículo $5 .^{\circ}$ de la ley general establece la obligatoriedad de la palabra «Cooperativa» en la denominación de la entidad, pero prohíbe su uso para cualquier otra persona que no se ajuste a las disposiciones de esta ley. 
Como otro elemento de innovación, dicho artículo admite la responsabilidad suplementada de las cooperativas en general, que constará, cuando así sea el caso, en la denominación de la misma.

Otra valiosa novedad introducida por la ley general, la constituye el enunciado de los principios cooperativos como normas de derecho positivo. El artículo $7 .^{\circ}$ de la ley general establece justamente la necesaria observancia de tales principios, los mismos que los exigidos en la Declaración de la $\mathrm{ACl}$, de 1995.

La ley general no se limita al enunciado como un elemento de mera información, sino que establece la obligación de aplicar los referidos principios al funcionamiento y organización de las cooperativas, así como su necesaria incorporación a las fuentes del derecho cooperativo, como principios generales y aportando un criterio de interpretación del derecho cooperativo.

Otro elemento innovador incorporado en la ley que comentamos y que ayuda al reconocimiento de la especificidad del derecho cooperativo y a la correcta interpretación de las normas que lo constituyen, es la definición del acto cooperativo, únicamente reconocido en la legislación anterior por el decreto-ley N. ${ }^{\circ}$ 15.645, aplicable sólo a las cooperativas agrarias, en tal específico contexto normativo.

La definición de acto cooperativo que resulta del art. $9 .{ }^{\circ}$ de la ley general coincide en términos generales con la doctrina, aunque con algunas especificidades, expresando que "Son actos cooperativos los realizados entre las cooperativas y sus socios, por éstas y los socios de sus cooperativas socias, o por las cooperativas entre sí cuando estuvieren asociadas bajo cualquier forma o vinculadas por pertenencia a otra de grado superior, en cumplimiento de su objeto social.

Los mismos constituyen negocios jurídicos específicos, cuya función económica es la ayuda mutua, quedan sometidos al derecho cooperativo y para su interpretación se entenderán integrados por las estipulaciones del estatuto social.

Tendrán por objeto la creación, modificación o extinción de obligaciones, negocios dispositivos en sentido amplio o en sentido estricto.

En caso de incumplimiento, la parte a la cual se le incumpla podrá optar entre la ejecución forzada y la resolución o rescisión según corresponda, más daños y perjuicios. Se deberá solicitar judicialmente y el Juez podrá otorgar un plazo de gracia.

En todo lo no previsto en las leyes cooperativas se aplicarán al acto cooperativo los principios generales en materia de negocio jurídico en general y de los contratos en particular, en lo compatible y en cuanto correspondiere o fuere pertinente.

Los vínculos de las cooperativas con sus trabajadores dependientes se rigen por la legislación laboral». 
Resulta indubitable la importancia del concepto de acto cooperativo incorporado en la ley ya que, entre otros anteriores inconvenientes, no había coincidencia, ni en el ámbito judicial, ni en el administrativo, respecto de su reconocimiento y mucho menos en cuanto a su aplicación a la generalidad de las formas o modalidades cooperativas, ya que hasta entonces sólo era derecho positivo en las Cooperativas Agrarias.

En cuanto a las modalidades de las cooperativas, la nueva ley simplifica su clasificación de acuerdo al objeto del acto cooperativo, en base al cual serán de trabajadores, de consumidores (o usuarios) o de trabajadores y consumidores a la vez (art. $10{ }^{\circ}$ ), sin perjuicio de definir y regular diez clases de cooperativas en la parte especial en función del tipo de actividad u objeto social, sin que la enunciación resulte, una vez más, taxativa.

También la nueva ley innova en esta parte general que establece la especificidad del fenómeno cooperativo y el derecho que lo rige, en cuanto a la posibilidad de transformación de las cooperativas de acuerdo con lo preceptuado en el art. $11 .^{\circ}$ de la misma, norma sujeta a la reglamentación del Poder Ejecutivo.

En nuestro país ha sido tradicional sostener la imposibilidad de transformación de las cooperativas en sociedades comerciales, así como la de fusionarse con ellas, en el contexto estructural y formal de éstas, ello, sin perjuicio de que se admitía la transformación de sociedades comerciales en cooperativas, la fusión entre ellas o la de una sociedad comercial con una cooperativa, siempre que la entidad absorbente o la nueva entidad que se cree fuera una cooperativa.

El legislador ha adoptado actualmente la siguiente posición: si bien el principio rector respecto de la transformación coincide con la doctrina más tradicional en la materia, es decir, la prohibición de transformación de las cooperativas en entidades de otra naturaleza, tipología o forma jurídica, siendo nula toda resolución en contrario, ha admitido una excepción, la que habilita tal transformación cuando a criterio de la Auditoría Interna de la Nación y del Instituto Nacional de Cooperativismo, (o sea, los organismos públicos de control y de promoción, respectivamente, este último creado en la misma ley), las circunstancias económicas y financieras de la cooperativa de la que se trate indiquen que constituye la única alternativa viable para mantener la continuidad de la unidad productiva y los puestos de trabajo.

La solicitud de transformación deberá provenir de una resolución de la Asamblea General Extraordinaria de la cooperativa, adoptada por una mayoría de por lo menos las $3 / 4$ partes del total de socios de la misma y presentarse en la Auditoría Interna de la Nación. Sin embargo, no podrá procederse a esa transformación sin contar con la autorización previa y fundada de ambos organismos, mencionados precedentemente. 
Surge de lo expuesto que, en lo que respecta al problema que planteaba la legislación anterior en cuanto a la confusa, incongruente y equívoca calificación jurídica de las cooperativas, la presente ley aporta soluciones normativas que no dejan lugar a dudas sobre la identidad única, diferencial y distinta de las entidades cooperativas, así como de un derecho especial, el derecho cooperativo, que las rige, sin perjuicio de que, aún en forma subsidiaria, no pueda prescindirse del derecho aplicable a las sociedades comerciales. No puede entonces hablarse de una autonomía absoluta del derecho cooperativo, pero sí de un avance importantísimo en el reconocimiento de la especialidad de ese derecho y de los principios generales que lo informan.

c) Soluciones al problema 3: Intensos y complejos sistemas y estructuras de contralor estatal, en perjuicio de la libre formación y desarrollo de las cooperativas

En cuanto al tercer problema planteado, relativo al sistema de contralor de las cooperativas, que ya había sido simplificado años antes de la promulgación de esta ley general, cabe expresar que la misma mantiene la solución de la ley N. ${ }^{\circ} 16.156$ en cuanto a inscripción y reconocimiento de la personería jurídica de las cooperativas, inscripción a hacerse en el Registro de Personas Jurídicas, creado por el artículo 294 de la ley 17.296 de 21 de febrero de 2001, que depende de la Dirección General de Registros del Ministerio de Educación y Cultura, pero innova en el sentido de la especificidad de las entidades cooperativas en cuanto crea en aquel una sección especial, la Sección Registro Nacional de Cooperativas, donde se inscribirán el acta de constitución y el estatuto de las cooperativas, los documentos de uso y goce previstos por el artículo 135 de la ley general (exclusivos para las cooperativas de vivienda) y todos los actos que alteren, modifiquen o extingan las inscripciones efectuadas.

En cuanto al control, se continúa con la fiscalización sobre las cooperativas a cargo de la Auditoría Interna de la Nación, excepto respecto de las cooperativas sociales, éstas, controladas por el Ministerio de Desarrollo Social, que podrá, sin embargo, solicitar el establecimiento de criterios técnicos de contralor a la Auditoría Interna de la Nación.

Surge de lo expuesto que existe en la ley general una clara diferenciación entre los roles de registro, control y promoción de las cooperativas.

1) el registro, a través del Registro de Personas Jurídicas - Sección Registro Nacional de Cooperativas- Dirección General de Registros del Ministerio de Educación y Cultura; 
2) el control estatal, se encuentra esencialmente centralizado en un organismo, la Auditoría Interna de la Nación, órgano desconcentrado del Ministerio de Economía y Finanzas, sin perjuicio de la colaboración, a través del cruce de información, que pueda darse entre los distintos organismos eventualmente interesados en estas entidades, y sin perjuicio, también de que, en lo atinente a algunas modalidades, como las cooperativas de intermediación financiera o seguros, éstas deben someterse al contralor del Banco Central del Uruguay respecto de sus respectivas actividades, o como las sociales, que están bajo el control del Ministerio de Desarrollo Social; y

3) la promoción, objeto de otro capítulo de la ley general y de este trabajo, está a cargo, primordialmente, del Instituto Nacional de Cooperativismo.

Por otra parte, se permite a las cooperativas contar con un servicio de auditoría externa con intervención de profesional habilitado, servicio que puede ser también prestado por otra cooperativa o entidad con intervención de profesional habilitado.

En definitiva, la legislación vigente ha continuado con la política de disminuir la intervención estatal en cuanto a la constitución así como con la de simplificación y reconocimiento de las cooperativas como personas jurídicas, y en cuanto a los organismos intervinientes y sobre el control de las mismas, aunque continúa, a nuestro criterio, un cierto paternalismo estatal con referencia a estas entidades, en clara diferenciación con lo que sucede respecto de otras entidades económicas del panorama jurídico-organizacional nacional, con la excepción, tal vez, de las sociedades anónimas, particularmente de las abiertas.

d) Soluciones al Problema 4: La deficiente regulación legal de la gestión cooperativa .

En cuanto al cuarto problema planteado, es decir, la limitada e insuficiente normatividad de la gestión social, cabe expresar, en relación a las soluciones impuestas por la nueva ley general, que se adopta la estructura organizacional generalmente más aceptada, o sea, la Asamblea General, que también puede ser de Delegados, el Consejo Directivo, al que se le reconoce facultades implícitas no otorgadas por la ley o el estatuto a la Asamblea General y las necesarias para la realización del objeto social, la Comisión Fiscal y otros órganos cuya previsión estará a cargo de los Estatutos, como ser, el Comité Ejecutivo, a cargo de miembros del Consejo Directivo para atender asuntos ordinarios de la cooperativa, el Comité de Recursos, delegado de la Asamblea General, 
para tramitar y resolver recursos atribuidos a su conocimiento o el de la Asamblea, por vía legal o estatutaria, las Comisiones Auxiliares, de carácter permanente o temporal designadas por el Consejo Directivo de su seno o de entre los socios, determinando sus funciones, la Comisión Electoral; exigiéndose además en las cooperativas de primer grado, una Comisión de Educación, Fomento e Integración Cooperativa. Todo ello, con particular nivel de desagregación, amplitud y detalle normativo.

Como vemos, la ley general ha solucionado las carencias que observábamos en la legislación anterior en lo atinente a la escasa regulación legal de los aspectos organizacionales y administrativos de las cooperativas, que dejaban excesiva discrecionalidad a los estatutos y por ende, se generaba la posibilidad de soluciones heterogéneas, eventualmente contradictorias y no necesariamente eficientes.

También se ha dedicado el capítulo III a determinar, y corresponde aquí destacarlo, las condiciones para integrar las cooperativas en calidad de socios, los deberes y derechos básicos de los mismos, y los motivos que autorizan la pérdida de la calidad de socio o su exclusión o suspensión, exigiendo un compromiso mucho más profundo de los mismos con la gestión de la cooperativa y el desarrollo de las actividades para el cumplimiento de su objeto social, a través de su participación directa, la obligación de desempeñar los cargos para los que fueran electos, salvo justa causa de excusa, la posibilidad de formular denuncias ante la Comisión Fiscal por incumplimientos a las normas que rigen la cooperativa, etc., todas ellas, disposiciones que, por un lado, tienden a homogeneizar el estatuto básico del socio para todas la modalidades cooperativas, sin perjuicio de las particularidades propias de las diferentes modalidades o las que señalen los estatutos en cada caso $y$, por otro, a hacer del socio un agente activo y comprometido dentro de la entidad que integra.

Como señalamiento, tal vez aunque no necesariamente menor, y en relación con la gestión, creemos que no se avanzó en una figura que consideramos importante para mejorar la competividad de las cooperativas en general, ya que si bien se autoriza la existencia de un Comité Ejecutivo para una gestión más ágil en asuntos ordinarios, no se previó la existencia de la Gerencia profesional, que a nuestro entender era un instrumento de gestión empresarial moderno y significativo para el desarrollo de la empresa cooperativa, que está prevista, en cambio, en la ley de sociedades comerciales, un instituto societario que podría ser extrapolado a las cooperativas en cuanto legislación de aplicación subsidiaria de la ley general, no previsto en ésta pero compatible con la misma. 
e) Soluciones al problema 5: La ausencia de un apropiado régimen jurídico de los aspectos económico-financieros de las cooperativas, en perjuicio de su desarrollo y consolidación.

La ley general ha desarrollado profusa y prolijamente el régimen económico-financiero de las cooperativas, dotando a éstas de instrumentos y recursos, tanto patrimoniales como no patrimoniales, y ello amerita cierto desarrollo en la oportunidad en cuanto ejemplo demostrativo de la preocupación del legislador sobre tales cuestiones.

El artículo 52 de la ley general establece los recursos patrimoniales, los que son concretamente regulados en las disposiciones siguientes de la ley para el cumplimiento del objeto social de las cooperativas, ellos son:

1) El capital social.

2) Los fondos patrimoniales especiales.

3) Las reservas legales, estatutarias y voluntarias.

4) Las donaciones, legados y recursos análogos que reciban destinados a incrementar el patrimonio.

5) Los recursos que se deriven de los otros instrumentos de capitalización.

6) Los ajustes provenientes de las reexpresiones monetarias o de valuación.

7) Los resultados acumulados.

La novedad más importante, a nuestro entender, se refiere a otros instrumentos de capitalización, en cuanto se prevén las participaciones subordinadas, las participaciones con interés y otros instrumentos de capitalización que puedan crearse.

Las participaciones subordinadas son recursos financieros aportados por socios o no socios que se incorporan al patrimonio de la cooperativa, sujetos al riesgo de la gestión y cuya remuneración queda subordinada a la existencia de excedentes netos de gestión de la cooperativa con arreglo a lo previsto en el art. 70 de la ley. Las participaciones con interés, que reconocen algún antecedente en la normativa cooperativa anterior, son definidos como recursos financieros aportados por socios o no socios que se incorporan igualmente al patrimonio de la cooperativa y también están sujetos al riesgo de la gestión, pero que se diferencian de los anteriores en cuanto reciben una remuneración con independencia de la existencia o no de excedentes netos de gestión.

Estimamos interesante lo que se establece respecto del destino de los excedentes netos: debe deducirse, en primer lugar, el abono de intereses a pagar a los instrumentos de capitalización y, en segundo lugar, lo correspondiente a la recomposición de los rubros patrimoniales cuando 
hayan sido disminuídos por la absorción de pérdidas de ejercicios anteriores. El remanente se distribuye de acuerdo al siguiente orden:15\% (mínimo) para la constitución de un fondo de Reserva Legal hasta que éste iguale al capital social, disminuyéndose un $10 \%$ a partir de ese momento y cesando al ser triplicado el capital: el 5\% (mínimo) para el Fondo de Educación y Capacitación Cooperativa, y el 10\% para una Reserva por concepto de operaciones con no socios. El saldo será destinado al reparto entre los socios en concepto de retorno o a pagar intereses a las partes sociales integradas hasta el máximo de interés corriente en plaza, según determinación de Asamblea.

El monto a repartirse entre socios en concepto de retorno no podrá ser inferior al 50\% del remanente y se distribuirá de acuerdo a los siguientes criterios: a) en las cooperativas de primer grado, en proporción a las operaciones efectuadas con la cooperativa o al trabajo realizado en ella; y b) en las cooperativas de segundo o ulterior grado, en proporción al capital social aportado o a los servicios utilizados, según establezca el estatuto.

Por resolución de Asamblea General, podrá resolverse la capitalización de los importes destinados a retorno e intereses sobre partes sociales.

Con respecto al reembolso de las partes sociales, cuando el socio haya perdido su condición de tal y haya saldado todas sus obligaciones para con la cooperativa, sólo tendrá derecho al reintegro de su capital integrado por su valor nominal o, en caso de previsión estatutaria o legal, en valores ajustados. Asimismo deberán adicionar o disminuir, según corresponda, los resultados acumulados no distribuídos y los del ejercicio en curso al momento de la pérdida de la calidad de socio.

Los reembolso de partes sociales, por resolución de Asamblea General, podrán suspenderse por hasta dos años en caso de pérdidas en el ejercicio económico. También pueden limitarse los reembolsos a las partes sociales, asociados a los requerimientos mínimos de capital en función de la actividad económica desarrollada por la cooperativa.

Por último, se establece la irrepartibilidad de otros recursos patrimoniales que no sean los anteriormente mencionados, que constituyen patrimonio propio e irrepartible de la cooperativa., sin posibilidad de ser repartidos ni acrecentar los aportes individuales de los socios.

En cuanto a los recursos no patrimoniales se establecen, por un lado, la emisión de obligaciones a suscribir por socios o terceros, acorde a condiciones que establezca la reglamentación (no dictada a la fecha de este trabajo) y también la posibilidad de crear e incrementar cuotas sociales o fondos especiales con aportes voluntarios u obligatorios de los socios o parte de los excedentes netos anuales, conforme al estatuto: 
Asimismo, se establece el Fondo de Educación y Capacitación Cooperativa, cuyas actividades pueden ser desarrolladas directamente por la cooperativa o a través de federaciones, confederaciones o entidades auxiliares, o conjuntamente con ellas.

Este Fondo se integrará con los excedentes netos del ejercicio que se asignen al mismo con un porcentaje mínimo del $5 \%$ y las donaciones y ayudas recibidas de terceros con ese destino específico. Un detalle del uso de dicho Fondo integrará el informe anual de la gestión que se presenta a la Asamblea General.

En el mismo capítulo se tratan las operaciones con no socios, las que la ley general autoriza por razones de interés social o cuando fuera necesario para el mejor desarrollo de su actividad económica, siempre que no comprometa su autonomía, bajo ciertas reglas y condiciones, a la vez que se establecen casos que no se consideran actos con terceros. Tales operaciones y su regulación reconocer antecedentes en soluciones legales y reglamentarias de larga data en el país, que eran aplicables a ciertos tipos de cooperativas y que constituian excepciones a la mutualidad subyacente en el sistema cooperativo anterior.

A esto cabe agregar el tema de la responsabilidad económica de los socios con la cooperativa y con los terceros, difiriendo a los estatutos establecerla entre dos opciones, la responsabilidad limitada (a los aportes suscritos) o la responsabilidad suplementada, la que no podrá superar veinte veces el aporte suscrito, no pudiendo por modificación estatutaria disminuirse el grado de responsabilidad, pero sí aumentarla.

Surge del análisis de las disposiciones reseñadas que la nueva ley ha otorgado a las cooperativas instrumentos económicos y financieros técnicamente idóneos para posibilitar su desarrollo empresarial en la economía moderna, superando las objeciones que merecía al respecto las insuficiencias de la legislación anterior.

f) Soluciones al problema 6: Insuficiente tratamiento de la integración cooperativa, en perjuicio de su misma subsistencia y de la unidad y coordinación del sistema cooperativo

En el Capítulo VI —que trata la Asociación, Fusión e Incorporaciónla nueva ley innova en nuestro derecho y sigue al respecto la tendencia mayoritaria de la legislación comparada al permitir, ya no con carácter particular sino general, la asociación, no sólo entre cooperativas sino con personas de otra naturaleza jurídica, sean públicas o privadas, así como tener en ellas participación, si así lo prevé el estatuto, a condición de que sea conveniente para su objeto social y que no se transfieran beneficios fiscales ni legales que les sean propios. 
La ley prevé también las Federaciones y Confederaciones, lo cual no constituye en si mismo una innovación en la materia.

En cuanto a las cooperativas de grado superior, resulta novedoso a nuestra legislación que también puedan integrarse a ellas en calidad de socios, personas jurídicas de otra naturaleza, públicas o privadas, y personas físicas, hasta un máximo del $20 \%$ del total del capital social de la cooperativa.

En cuanto a su actividad, de conformidad a la ley que nos ocupa y a sus propios estatutos, podrán prestar servicios de carácter técnico, económico, social, cultural y asumir la representación de sus miembros. Asimismo, podrán un establecer un régimen de representación y voto proporcional al número de socios, al capital aportado, uso de los servicios u otros criterios que establezca el estatuto.

El Capítulo VII de la ley, que prevé Otras Modalidades de Colaboración Económica, incorpora otras innovaciones:

El artículo 89 regula las Corporaciones cooperativas, es decir, aquellas asociaciones empresariales que, constituidas mayoritariamente por cooperativas de primer y segundo o ulterior grado, tengan por objeto la definición de políticas empresariales, su control y, en su caso, la planificación estratégica de la actividad de sus socios, así como la gestión de los recursos y actividades comunes. Las mismas se regirán por un órgano de dirección y también un órgano de fiscalización y serán reguladas, por este artículo de la ley y subsidiariamente, por lo dispuesto para las cooperativas de segundo o ulterior grado.

El artículo 90, a su vez, regula las llamadas Cooperativas mixtas en las que existen socios minoritarios cuyo derecho de voto en la Asamblea General se podrá determinar, de modo exclusivo o preferente, en función del capital aportado, representado por certificados, constancia de aportes u otros documentos o títulos. El derecho a voto en estas cooperativas se distribuye, al menos un $51 \%$, en la proporción que establezca el estatuto, a socios cooperativistas y una cuota máxima, a determinar estatutariamente, del $49 \%$, de los votos se distribuirá en acciones con voto, pasibles de negociarse en el mercado, si el estatuto así lo prevé.

En el caso de las acciones con voto, tanto los derechos y obligaciones de sus titulares como el régimen de los aportes se regularán por el estatuto y por lo dispuesto en la legislación de sociedades anónimas y tributarias, para las acciones.

Los resultados imputables a los poseedores de acciones con voto se distribuirán entre ellos en proporción al capital desembolsado. Para los otros, se utilizarán los criterios generales definidos en la ley para las cooperativas de primer grado.

También resulta una innovación lo dispuesto en el artículo 91, relativo a las Secciones, es decir, que la cooperativa podrá realizar, a través 
de tales secciones, actividades económico-sociales específicas, complementarias del objeto principal, que llevarán una contabilidad independiente y serán representadas y gestionadas por el Consejo Directivo de la cooperativa.

El volumen de operaciones de una sección no podrá superar el $20 \%$ del volumen total de operaciones de la cooperativa y en forma conjunta, no podrán superar el $50 \%$ del total de operaciones.

Las cooperativas que dispongan de alguna sección estarán obligadas a contar con un servicio de auditoría externa anual.

Las secciones serán reguladas por todas las normas legales y reglamentarias correspondientes al tipo de cooperativa o actividad que desarrolle cada sección, excepto los beneficios legales. Tampoco se transfieren a las secciones los beneficios fiscales ni legales que provenga del tipo de actividad $u$ objeto principal de la cooperativa.

Es advertible en la especie que la ley general ha incursionado profundamente en el fenómeno de la integración, en contraste con lo que había ocurrido en la normativa cooperativa anterior.

g) Soluciones al Problema 7: El insuficiente y heterogéneo sistema legal do apoyo al desarrollo de las cooperativas, que se traduce en restricciones en el fenómeno cooperativo, en perjuicio de la estabilidad y desarrollo del cooperativismo.

La ley general responde a este problema en el Título III de la misma, encabezándolo con una disposición de carácter programático en el que se mencionan la promoción, por parte del Estado, de políticas públicas orientadas al sector cooperativo y de la economía social en general, facilitación del acceso a fuentes de financiamiento públicas y privadas, apoyo de Ministerios y áreas en todo programa compatible con los contenidos en los planes de desarrollo cooperativo.

En cuanto a la tributación, como instrumento de promoción, la ley general establece algunos tratamientos diferenciales entre las distintas modalidades cooperativas, basadas en ciertas exoneraciones.

Pero indudablemente, la gran novedad en materia de promoción, y su separación respecto del registro y control, es la institucionalización de la misma con la creación del Instituto Nacional del Cooperativismo INACOOP), como persona jurídica de derecho público no estatal, al que se le cometen la proposición, asesoramiento y ejecución de la política nacional del cooperativismo para promover el desarrollo económico, social y cultural del sector cooperativo y su inserción en el desarrollo del país, entidad a la que se les dota de todos los cometidos y atribuciones conducentes y necesarios para la realización de esos objetivos. 
Su regimen jurídico es prevalentemente el de la actividad privada; el control estatal sobre el Instituto es ejercido por la Auditoría Interna de la Nación y el Tribunal de Cuentas de la República.

Los órganos del Instituto son el Directorio, la Dirección Ejecutiva y el Consejo Consultivo del Cooperativismo.

El Directorio se integra por cinco miembros, tres delegados del Poder Ejecutivo y dos delegados del sector cooperativo. Los representantes del sector cooperativo son designados por el Poder Ejecutivo a propuesta de la Confederación Uruguaya de Entidades Cooperativas (CUDECOOP), de una nómina de seis personas y si no se formalizara la proposición de estos representantes, el Poder Ejecutivo los designará de oficio. El mandato de los miembros del Directorio es de dos años, pudiendo ser reelectos por dos períodos más.

Por otra parte, hay un Director Ejecutivo, cuya designación debe recaer sobre aquella persona que demuestre tener una sólida formación en materias propias del Instituto, con atribuciones de ejecutar los planes, programas y resoluciones aprobados por el Directorio; realizar todas las tareas inherentes a la administración del personal y a la organización del Instituto; promover el relacionamiento del Instituto con entidades nacionales e internacionales a fin de facilitar el cumplimiento de los cometidos del mismo; promover el fortalecimiento de la cooperación técnica internacional, con énfasis en la coordinación con institutos de otros países y toda otra que el Directorio le encomiende o delegue.

Por último, el Consejo Consultivo del Cooperativismo, está integrado por representantes de carácter honorario, de cada una de las clases de cooperativas previstas en la ley, más dos representantes de la Universidad de la República y dos de la Administración Nacional de Educación Pública.

El Consejo es un órgano de consulta del Instituto, y actúa convocado por el Directorio o a solicitud de cinco de sus miembros.

Asesora en la elaboración del Reglamento General del Instituto, en la elaboración de planes y programas, cuando el Directorio lo solicite, en la reglamentación de su propio funcionamiento y opinando en toda otra cuestión relacionada con el cooperativismo y la economía social cuando lo estime conveniente.

Las fuentes de financiamiento del Instituto son variadas pero entre ellas se incluye una prestación coactiva anual que se crea para promoción, desarrollo y educación cooperativa, cuyo hecho generador lo constituye el desarrollo de actividades propias de las cooperativas en el ámbito de su naturaleza específica y se considera configurado al cierre del ejercicio económico de la cooperativa. El Sujeto activo es el INACOOP, y los sujetos pasivos las cooperativas de primer, segundo o ulterior grado 
que operen en el país, salvo excepciones parciales o totales previstas en la misma ley.

La ley crea además el Fondo Rotatorio Especial (FRECOOP) cuyo destino es el cofinanciamiento de proyectos de inversión para la viabilidad y desarrollo de las empresas cooperativas, cualquiera sea su clase o grado.

Este Fondo se administra por el INACOOP y se establece en función del programa anual de las actividades que financie este Fondo, asi como los criterios y prioridades para la asignación del mismo.

h) Otras disposiciones de interés de la Ley General de Cooperativas.

Sin perjuicio de otras normas de carácter común y general como las relativas a la disolución y liquidación de las cooperativas, encontramos el Título II, que trata de las Cooperativas en particular, en relación a las cuales sólo habrían quedado plasmadas en la ley las disposiciones que se estimaron necesarias o convenientes de acuerdo con las particularidades de las diversas clases de cooperativas, clasificadas de acuerdo a su actividad o a su objeto social aunque, como ya lo expresáramos, la clasificación resultante no es taxativa.

Así por ejemplo:

El artículo 100 define a las cooperativas de trabajo como las que tienen por objeto proporcionar a sus socios puestos de trabajo y distingue dos formas: por un lado, "una organización conjunta destinada a producir bienes o servicios en cualquier sector de la actividad económica» y, por otro, las que tienen por objeto» la comercialización en común de productos o servicios, siempre que sus socios no tengan trabajadores dependientes y el uso de medios de producción de propiedad del socio esté afectado exclusivamente al cumplimiento del objeto de la cooperativa».

La ley establece que la relación de los socios de la cooperativa con la misma es de carácter societario y sus remuneraciones mensuales son a cuenta de excedentes, aunque no pueden ser inferiores al laudo y demás beneficios sociales establecidos por la normativa vigente o convenio colectivo aplicable al ramo de actividad, lo que excluye a dichos socios de la estricta subordinación a un patrón, es decir, de la calidad de simples empleados.

Con respecto a la tributación, sin perjuicio de exoneraciones significativas y diversas, se faculta al Poder Ejecutivo a establecer un régimen ficto de aportación como único aporte a la seguridad social para aquellas cooperativas de trabajo con un volumen de actividad a ser fijado por la reglamentación, así como a disponer un régimen de excepciones y exoneraciones de tributos creados o por crearse, destinado a fomentar el desarrollo de estas entidades cooperativas. 
Quizás la innovación más importante en cuanto a la promoción de estas cooperativas la constituye la establecida en los artículos 104 y 105 de la ley, disposición, la primera, en cuanto otorga prioridad a efectos de la adjudicación como unidad, de una empresa en proceso liquidatorio concursal, a las cooperativas de trabajo constituidas por parte o la totalidad del personal de dicha empresa.

En tales casos, y a solicitud de parte, el organismo de previsión social podrá disponer el pago al contado y por adelantado de los importes del subsidio por desempleo que correspondiere a los trabajadores socios, siempre que sean destinados en su totalidad, como aportación de partes sociales a la cooperativa a efectos de su capitalización.

Asimismo, en las empresas cuyo proceso de liquidación ya se haya iniciado, el Juez competente podrá designar depositario de los bienes de las mismas, y para su uso precario, a la cooperativa de trabajo que se haya constituido con la totalidad o parte del personal; solución, ésta, que ya había sido incorporada a una ley anterior en materia de tales cooperativas de 2004.

Nos interesa señalar que la nueva ley concursal uruguaya, ley 18.387, que entró en vigencia el 3 de noviembre de 2008, también incluyó normas que presentan soluciones de relativa similitud a las previstas por la ley general, con las particularidades siguientes:

1) el art. 172 de la citada ley concursal prevé igualmente la referida prioridad en el caso de la subasta en bloque de la empresa en liquidación, a igualdad de ofertas, con la particularidad de que los trabajadores de la empresa en liquidación, o por lo menos la mayoría de ellos, pueden optar entre la formación de una cooperativa de trabajo o de una sociedad comercial en la que por lo menos más del 50\% del capital social pertenezca a dichos trabajadores, y en este último caso, de ser una sociedad anónima, las acciones de éstos deban ser nominativas y no endosables;

2) el art. 174 núm. 2 de esa misma ley concursal tiene también una disposición similar a la contenida en la ley general respecto de la posibilidad de asignar, bajo forma de depósito, el uso precario de los bienes de la empresa en liquidación a una cooperativa de trabajo formada total o parcialmente por trabajadores de esa empresa, pero en este caso la decisión judicial requiere, entre otros presupuestos, que no haya habido venta en bloque de aquella, que se ingrese a la etapa de liquidación de la misma por partes y que exista riesgo de que ciertos créditos laborales privilegiados no puedan ser satisfechos en su totalidad; 
3) el art. 238 de la misma ley consursal, bajo la denominación de «abandono de la empresa», habilita la solución anterior, la que puede transformarse en una cesión definitiva de la empresa, a una cooperativa de trabajo o, incluso, a otra modalidad empresarial que formen los trabajadores, en la hipótesis de que, en principio, sólo existan acreedores laborales.

El artículo 105, por su parte, en cuanto prevé la posibilidad de que en dichos casos la cooperativa pueda solicitar al Ministerio de Trabajo y Seguridad Social la suspensión de la aplicación del laudo aplicable, sólo respecto de los socios de la cooperativa, durante los tres primeros años de su funcionamiento, previéndose asimismo, en los casos del artículo 104, arriba citado, la realización de horas de trabajo solidarias de carácter gratuito por parte de los socios, que no generen aporte alguno a la seguridad social.

Por otra parte. Las cooperativas de trabajo, siempre que hayan surgido como consecuencia de un proceso de liquidación, moratoria, cesación de pago o situación similar de la empresa titular anterior de la unidad productiva, estarán temporalmente exentas de la prestación anual coactiva referida oportunamente; exoneración ésta que regirá sólo por cinco años a partir de que la cooperativa comience a producir, art. 205.

En lo atinente a Cooperativas de Consumo, únicamente se proporciona su definición y se establece que sólo podrán adoptar la responsabilidad limitada para sus socios, rigiéndose por las disposiciones generales de la ley.

Respecto del capítulo destinado a las Cooperativas Agrarias, muchas de sus anteriores soluciones fueron incorporadas en la parte general de esta ley, por lo que la parte especial mantiene sólo la definición, las condiciones para ser socio y la conformación de los saldos deudores para constituir título ejecutivo.

Las Cooperativas de Vivienda son las más extensamente reguladas, ya que lo relativo a éstas, previstas en el capítulos $X$ de la ley 13.728, de 1968 , derogado por esta ley general, fue integrado, con algunas variantes, a la ley general.

En cuanto a las Cooperativas de Ahorro y Crédito, se distinguen dos modalidades, las de intermediación financiera o las de capitalización.

Las primeras están comprendidas en el ámbito de aplicación del decreto-ley 15.322, de 17 de setiembre de 1982, ley de intermediación financiera, modificativas y concordantes, y sometidas en lo pertinente al contralor del Banco Central del Uruguay. Las de capitalización, que no reciben depósitos de sus socios ni de terceros, son controladas por la Auditoría Interna de la Nación. 
La ley general, en relación a las cooperativas de capitalización, tiene disposiciones rigurosas para limitar la concentración de riesgos y controlar los pasivos financieros cuando los fondos con que la cooperativa realiza operaciones no provienen del capital aportado por sus propios socios, así como limita el monto de los créditos que se otorguen a los socios, grupo económico o familiar, con ciertas liberalidades cuando se trate de socios que realicen actividades de micro o pequeña empresa, en cuyo caso no regirán las limitaciones previstas.

Los límites en las cooperativas de intermediación financiera, por su parte, los establece el Banco Central del Uruguay.

En cuanto a las Cooperativas de Seguros y a las de Garantía Recíproca sólo se incluye su definición, en tanto sus formas y actividades se rigen por leyes especiales.

También se prevén las denominadas Cooperativas Sociales, ya anteriormente reguladas, que son un sub tipo modalizado y atemperado de las cooperativas de trabajo, que además de proporcionar a sus socios un puesto de trabajo para el desarrollo de distintas actividades económicas, (agropecuarias, industriales, comerciales o de servicios), pretende lograr la inserción social y laboral de los jefes y jefas de hogares pertenecientes a sectores con necesidades básicas insatisfechas, jóvenes, discapacitados, minorías étnicas y todo grupo en situación de extrema vulnerabilidad social. Un mínimo del 75\% de los socios justamente, deberá pertenecer a sectores en situación de vulnerabilidad social.

También como novedad en cuanto a modalidades respecto a la anterior legislación, se incorporan las cooperativas de artistas y oficios conexos, en realidad, otro sub tipo de cooperativas de trabajo, pero cuyos integrantes son personas físicas calificadas como artistas, intérpretes o ejecutantes o que desarrollen actividades u oficios conexos a las mismas, pudiendo integrarlas quienes estén inscriptos en el Registro Nacional de Artistas y Actividades conexas del Ministerio de Trabajo y Seguridad Social.

\section{A modo de conclusión}

La presente colaboración está esencialmente dirigida a exponer las principales soluciones, preferentemente innovadoras, que aporta la ley concursal uruguaya de 2008, del Uruguay, la que requerirá ahora, más allá de su prevista reglamentación un análisis más profundo de sus términos y una prudente espera de su práctica negocial, judicial y administrativa, a los efectos de su oportuna evaluación.

El tiempo dirá si es adecuada a las exigencias, necesidades y expectativas del cooperativismo uruguayas en general y de las cooperativas en particular. 